\title{
Case control study of supervised and unsupervised medical abortion in first trimester of pregnancy
}

\author{
ShikhaVerma*, Rita Ranjan, Megha Batra
}

Department of Obstetrics and Gynaecology, DDU Hospital, Hari Nagar, New Delhi-64, India

Received: 23 May 2016

Accepted: 11 June 2016

\section{*Correspondence:}

Dr. Shikha Verma,

E-mail: shikhav48@yahoo.com

Copyright: $\odot$ the author(s), publisher and licensee Medip Academy. This is an open-access article distributed under the terms of the Creative Commons Attribution Non-Commercial License, which permits unrestricted non-commercial use, distribution, and reproduction in any medium, provided the original work is properly cited.

\section{ABSTRACT}

Background: The MTP act of India 1971 provides for the termination of pregnancy up to 20 weeks of gestation, by a registered medical practitioner, provided all the prerequisites are fulfilled. The objective of this study was to conduct case control study of supervised and unsupervised medical abortion in first trimester of pregnancy.

Methods: A case control study was conducted with two groups of patients with period of gestation $<9$ weeks. Case group consist of 30 patients presenting to emergency department with unsupervised intake of medical abortion pill. Control group consist of 30 patients presenting to family planning outpatient department want medical abortion pill under supervision. The main outcome variables were comparison of success rate, failure rate, complications like pain, fever, heavy bleeding, shock, requirement of blood transfusion. Interventions required were compared in both the groups in terms of medical management, surgical evacuation and laparotomy.

Results: In our study, the success rate achieved in terms of complete abortion was $66.7 \%$ in the supervised and $13.3 \%$ in the unsupervised group with ( $\mathrm{p}$ value $<0.001$ ). The complication rate was $60 \%$ in the supervised group in contrast to $93.3 \%$ in the unsupervised group. 56.7\% patients in unsupervised group required blood transfusion which was nil in supervised groups. $71.4 \%$ patients in the supervised group did not require intervention. In the unsupervised group, $13.8 \%$ required medical management, $65.5 \%$ required surgical evacuation and $6.7 \%$ had to undergo laparotomy for ectopic pregnancy.

Conclusions: In present study we conclude that first trimester medical abortion under supervision is more effective, safe and convenient as compared to unsupervised medical abortion. We recommend that government must stop over the counter sell of medical abortion pills.

Keywords: Medical abortion, Ultrasound, Mifepristone, Misoprostol

\section{INTRODUCTION}

The MTP act of India 1971 provides for the termination of pregnancy up to 20 weeks of gestation, by a registered medical practitioner, provided all the prerequisites are fulfilled. After the legalization of abortion facilities, a large number of women are seeking termination of pregnancy. WHO recommendations on medical abortion are restricted to early first trimester up to 63 days since last menstrual period. ${ }^{1}$ Anti-progesterone drugs like mifepristone (RU486), prostaglandin like misoprostol have been approved by United States food and drug Administration for medical abortion. ${ }^{2}$ Medical abortion is offered only to those patients, who are ready for follow up visits, can understand the instructions and ready for surgical procedure if failure or excessive bleeding occurs. The medical approach avoids the use of anaesthesia and the possibility of using it as an outpatient procedure. It has been perceived that medical abortions are extremely safe option even in the hands of untrained personal, leading to it's over the counter dispensing and possibly leading to an increase in unsupervised terminations and life threatening complication. ${ }^{3}$ With self-administration of medical abortion pill, sometimes life threatening conditions like ectopic pregnancy can be missed and may endanger life of women. In our country, very few 
restrictions are present regarding the sale of medical abortion pills and hence these are freely available to each and every one. The use of these drugs without proper knowledge can cause lot of morbidity among less aware women. Thus, a wonderful medicine which can be a boon can be transformed into a curse. Hence we need to regulate guidelines and formulate new rules, restricting the sale of these pills without medical practitioner's prescriptions. With this background in mind, the present study is designed to compare supervised and unsupervised medical abortion and study their complications.

\section{METHODS}

The present study was carried out in the department of obstetrics and gynaecology, Deen Dayal Upadhyay Hospital, New Delhi, India from January 2013 to September 2014. This study is a case control study consisting of two groups of patients.

Case (group US): 30 patients presenting to the emergency of obstetrics and gynaecology department with unsupervised intake of medical abortion pill within 9 weeks. POG control (group S): 30 patients presenting to the family planning outpatient department with period of gestation $<9$ weeks and desiring medical abortion.

\section{Inclusion criteria}

Women seeking medical termination of pregnancy during first trimester with gestational age up to 9 weeks were included in the study. Both the groups of patients were enrolled in study after taking an informed consent. They were explained all the steps and asked for a follow up. Patients with allergy to mifepristone or misoprostol, History of coagulation disorder, on anticoagulants and corticosteroid therapy, previous caesarean section and previous surgery on uterus or cervix, multiple pregnancy, chronic adrenal failure, inherited porphyria's were excluded from study. Both the groups were subjected to a detailed clinical history and examination. Laboratory and imaging investigation included blood grouping and rhesus typing, haemoglobin, total leucocyte count, differential leucocyte count, platelet count. Ultrasound to confirm intrauterine pregnancy, assess the period of gestation, rule out any retained products of conception in case of history of bleeding.

\section{Type of intervention in group-S}

After detailed clinical history and necessary investigations, all the 30 patients presenting to family planning OPD were given single tablet of mifepristone $200 \mathrm{mg}$ swallowed under supervision and called after 48 hours, four tablets $(800 \mu \mathrm{g})$ of tablet misoprostol were given and were observed for 4 hours. Patients were asked to report to the hospital, in case of any complication like heavy bleeding, cramps like pain, fever. They were monitored for expulsion of products of conception, bleeding and complete abortion. Day 2 after full regimenrepeat haemoglobin was done after abortion on day 2. An ultrasound done to check completeness of abortion. In case of failure we will go for other intervention.

\section{Type of intervention in group-US}

We included 30 women presenting to emergency department of obstetrics and gynaecology with history of intake of MTP pill purchased over the counter without consulting a registered medical practitioner. After admission a detailed history, examination and investigations are done. Women presenting with pain and with ultrasound suggestive of complete abortion were managed conservatively with antibiotics and NSAIDS. Women presenting with bleeding per vaginum and pain abdomen were advised USG to rule out incomplete abortion. Royal women's hospital recommendations of management depend on the findings in the ultrasonography. ${ }^{4}$

Patients with USG sign of RPOC $>3 \mathrm{~cm}$ were prepared for surgical evacuation, $\mathrm{RPOC}=1.5-3 \mathrm{~cm}$ were managed medically and RPOC $<1.5 \mathrm{~cm}$ expectant management was followed. Patients with severe bleeding per vaginum with features of shock, resuscitative measures were taken and blood transfusion if required. Once patient's condition improved surgical intervention was done. Patients with undiagnosed ectopic pregnancy had to undergo immediate laparotomy after confirmation on USG. All the patients were again followed up at day 2 with repeat haemoglobin and ultrasound.

Efficacy/success rate was evaluated in terms of complete abortion and compared in both the groups. Number of cases in which other intervention were required in form of surgical evacuation, laparotomy, medical treatment and no intervention done were also compared in both groups. Haemoglobin level assessed at the time of admission and classifying them in range of anaemia. Number of patients requiring blood transfusion. Safety and acceptability evaluated in terms of complication rate that is number of patients presenting with pain, fever, heavy bleeding and shock

\section{Statistical evaluation}

Statistical testing was conducted with the statistical package for the social science system version SPSS 17.0. Nominal categorical data were compared using Chisquared test or Fisher's exact test whereas continuous variables by using student's $t$ test. $P$ value $<0.05$ was considered statistically significant.

\section{RESULTS}

In the present study both the groups were comparable based on demographic variables like age, education, socio-economic status and period of gestation as shown in Table 1. The mean age of patients in supervised group 
and unsupervised group was found to be 29.60 years with S.D of 3.7. And 28.10 years with SD of 4.1 respectively. Both the groups were comparable based on mean age ( $\mathrm{p}$ value $=0.144)$.

Table 1: Demographic variables of study groups.

\begin{tabular}{|c|c|c|c|}
\hline Characteristics & $\begin{array}{l}\text { Case } \\
\text { group } \\
(n=30)\end{array}$ & $\begin{array}{l}\text { Control } \\
\text { group } \\
(n=30)\end{array}$ & $\begin{array}{l}P \\
\text { value }\end{array}$ \\
\hline Age groups & $28.10 \pm 4.10$ & $29.60 \pm 3.73$ & 0.144 \\
\hline \multicolumn{4}{|l|}{ Gravida } \\
\hline 1 & 0 & 0 & \multirow[t]{5}{*}{0.759} \\
\hline 2 & $33.3 \%$ & $43.3 \%$ & \\
\hline 3 & $46.7 \%$ & $40.0 \%$ & \\
\hline 4 & $16.7 \%$ & $16.7 \%$ & \\
\hline 5 & $3.3 \%$ & 0 & \\
\hline $\begin{array}{l}\text { Period of } \\
\text { gestation } \\
\text { (in weeks) }\end{array}$ & $7.00 \pm 1.26$ & $6.70 \pm 1.21$ & 0.350 \\
\hline \multicolumn{4}{|l|}{ Education } \\
\hline Illiterate & $20 \%$ & $6.7 \%$ & \multirow[t]{5}{*}{0.249} \\
\hline Up to $8^{\text {th }}$ & $26.7 \%$ & $26.7 \%$ & \\
\hline Up to $10^{\text {th }}$ & $20 \%$ & $33.3 \%$ & \\
\hline Up to $12^{\text {th }}$ & $30 \%$ & $20 \%$ & \\
\hline Graduate & $3.3 \%$ & $13.3 \%$ & \\
\hline \multicolumn{4}{|c|}{ Socio-economic status } \\
\hline $\mathrm{H}$ & $20 \%$ & $26.7 \%$ & \multirow[t]{3}{*}{0.518} \\
\hline $\mathrm{L}$ & $36.7 \%$ & $23.3 \%$ & \\
\hline M & $43.3 \%$ & $50 \%$ & \\
\hline \multicolumn{4}{|c|}{ Source of medical abortion } \\
\hline $\mathrm{C}$ & $80 \%$ & 0 & \multirow[t]{3}{*}{$<0.001$} \\
\hline G & 0 & $100 \%$ & \\
\hline $\mathrm{P}$ & $20 \%$ & 0 & \\
\hline $\begin{array}{l}\text { Hb on admission } \\
\text { (in gram) }\end{array}$ & $6.75 \pm 2.19$ & $9.27 \pm 0.922$ & $<0.001$ \\
\hline
\end{tabular}

Both the groups were comparable based on gravida ( $p$ value $=0.759$ ), where majority of patients were gravida 2 and gravida $3,83.3 \%$ in the supervised group and $80 \%$ in the unsupervised group.

$50 \%$ of patients in supervised group were para 2 whereas $40 \%$ in unsupervised resulting in comparable results ( $\mathrm{p}$ value $=0.30$ ).

Majority of patients in both the groups were between 6-8 weeks with mean age of 6.7 and 7 weeks in supervised and unsupervised group respectively.

The supervised group had majority of patients who had studied up to class $10^{\text {th }}(33.3 \%)$ and only $6.7 \%$ were illiterate which was comparable to the unsupervised group, where $30 \%$ had studied up to class $12^{\text {th }}$ and $20 \%$ were illiterate.
Majority of patients in both the groups belonged to middle class between $40-50 \%$.

The study suggests that $80 \%$ patients in the unsupervised group had taken the pill from the chemist shop without prescription and $20 \%$ from private practitioner denoting misuse of the abortion pills.

Table 2: Outcome variables of study groups.

\begin{tabular}{|llll|}
\hline Variables & $\begin{array}{l}\text { Case } \\
\text { group } \\
(\mathbf{n = 3 0})\end{array}$ & $\begin{array}{l}\text { Control } \\
\text { group } \\
(\mathrm{n}=30)\end{array}$ & $\begin{array}{l}\text { P } \\
\text { value }\end{array}$ \\
\hline Complications & & & \\
\hline Nil & $6.7 \%$ & $40 \%$ & 0.005 \\
\hline Fever & $23.3 \%$ & $20 \%$ & 0.754 \\
\hline Pain abdomen & $83.3 \%$ & $46.7 \%$ & 0.003 \\
\hline Heavy bleeding & $36.7 \%$ & 0 & $<0.001$ \\
\hline Shock & $23.3 \%$ & 0 & 0.011 \\
\hline BT REQD & & & 0.0003 \\
\hline Nil & $63.3 \%$ & $100 \%$ & \\
\hline 1 BT & $6.7 \%$ & 0 & 0.492 \\
\hline 2 BT & $20 \%$ & 0 & 0.024 \\
\hline 3 BT & $10 \%$ & 0 & 0.237 \\
\hline Outcome & & & \\
\hline Success & $13.3 \%$ & $66.7 \%$ & $<0.001$ \\
\hline Failure & $83.3 \%$ & $26.7 \%$ & $<0.001$ \\
\hline Lost to follow up & $3.3 \%$ & $6.7 \%$ & 1.000 \\
\hline Intervention & & & \\
\hline No intervention & $13.8 \%$ & $71.4 \%$ & $<0.001$ \\
\hline Medical management & $13.8 \%$ & $17.9 \%$ & 1.000 \\
\hline Surgical evacuation & $65.5 \%$ & $10.7 \%$ & $<0.001$ \\
\hline Laparotomy & $6.7 \%$ & 0 & 0.491 \\
\hline Vatables & & \\
\hline
\end{tabular}

Variables are given as mean \pm S.D or percentage unless otherwise indicated.

The mean $\mathrm{Hb}$ level of supervised group is 9.27 gram with S.D of 0.922 and of unsupervised group 6.75 gram with S.D of 2.19 in the unsupervised group. $53.3 \%$ patients in unsupervised group had moderate anemia, 30\% had severe anemia and $16.7 \%$ had very severe anemia. Thus $56.7 \%$ patients in this require B.T which was nil in supervised groups. This study shows significant difference in the two groups based on $\mathrm{Hb}$ level and requirement B.T with $\mathrm{p}$ value $<0.001$ and 0.024 respectively. The complication rate was $60 \%$ in the supervised group in contrast to $93.3 \%$ in the unsupervised group. Pain was the only complain in the supervised group, whereas the unsupervised group $83.3 \%$ presented with pain, $36.7 \%$ with haemorrhage and $23.3 \%$ presented in shock, which was statistically significant.

In our study, outcome variables success rate, failure rate, complications, intervention required as shown in Table 2. The success rate achieved in terms of complete abortion was $66.7 \%$ in the supervised and $13.3 \%$ in the unsupervised group. Failure rate was $26.7 \%$ in supervised group and $66.7 \%$ in unsupervised group. There was 
significant statistical difference between both groups based on success and failure rate with $\mathrm{p}$ value $<0.001$.

$71.4 \%$ patients in the supervised group did not require intervention. In the unsupervised group, $13.8 \%$ required medical management, $65.5 \%$ required surgical evacuation and $6.7 \%$ had to undergo laparotomy for ectopic pregnancy.

\section{DISCUSSION}

As per WHO, medical methods of abortion have been proven to be safe and effective when practiced under medical supervision. Patient selection is very important and contra-indication of medical abortion must be ruled out. Despite this recommendation there is over the counter dispensing and unsupervised termination of pregnancy, which are life-threatening.

\section{Age}

In our study, the mean age of women in supervised group in the supervised group and unsupervised group is 29.60 years with S.D of 3.7 and 28 year with S.D of 4.1 respectively. Other studies also showed similar results with the maximum age range of 20-29 years with $66 \%$ patients in the study conducted by Ojha $\mathrm{N}$ et al on unsupervised group, $54 \%$ in the study conducted by Thaker RV et al on self-administration of abortion pill. ${ }^{5,6}$

\section{Period of gestation (in weeks)}

In our study, maximum number of patients were in the gestational age 6 week and 7 week with $60 \%$ and $50.4 \%$ in supervised group and unsupervised group respectively pregnancy either by urine pregnancy test or overdue of periods. Our findings are in conformity with the study conducted by Thaker RV, where $43.2 \%$ presented at 6 weeks followed by $37.8 \%$ at 8 weeks. Another study conducted by Mishra $\mathrm{N}$ et al on unsupervised group maximum number of patients $60.5 \%$ had POG 7 weeks and above followed by POG <5 weeks in $26.7 \%$.

\section{Source of medical abortion}

In supervised group all the patients were advised medical abortion by a registered medical practitioner in DDU, hospital. Whereas in unsupervised group $80 \%$ had received the abortion pills from chemist shop without prescription and $20 \%$ from private other studies on unsupervised group showed similar results where $77.2 \%$ patients in the study by Mishra $\mathrm{N}$ et al and $100 \%$ in Thakar RV et al study received medical abortion from chemist shop. ${ }^{5,6}$

\section{BT Requirement}

In the present study none of the patients in supervised group require blood transfusion, which was $11(36.6 \%)$ in the unsupervised group. From the above data we conclude, that unsupervised use of abortion pill without prior $\mathrm{Hb}$ level may predispose to severe anemia requiring blood transfusion. In another study conducted by Deshpande $\mathrm{S}$ et al, no women require BT in patients in whom medical abortions were given under supervision. Studies in unsupervised group showed similar results, $16.7 \%$ require BT in the study conducted by Thaker RV et al and $5.8 \%$ in the study by Mishra $\mathrm{N}$ et al. ${ }^{6-8}$

\section{Complications}

Complications were common in the unsupervised group with $83.3 \%$ patients presenting with pain abdomen followed by heavy bleeding in $36.7 \%, 23.3 \%$ with fever and $23.3 \%$ presented with shock. This data suggests that supervised medical abortion is safe and acceptable to the patients whereas, unsupervised medical abortion may land up in severe complication like shock, heavy bleeding, and sepsis. Our findings were in conformity with the study conducted by Thaker RV et al $18.9 \%$ presented with pain abdomen, $89.1 \%$ heavy bleeding, $25.4 \%$ presented in shock, $8.1 \%$ presented in fever. Another study conducted by Mishra $\mathrm{N}$ et al $13.9 \%$ patients presented in shock and $60 \%$ with heavy bleeding. 6,7

\section{Outcome}

Our study concluded a success rate of $66.7 \%$ and $13.3 \%$ in the supervised and unsupervised group respectively. A failure rate $26.7 \%$ was reported in supervised group and $83.3 \%$ in unsupervised group. This data suggests that supervised medical abortion is effective method, whereas unsupervised medical abortion mostly land up in failure, so it should not be recommended.

Other studies showed similar results. On supervised group studies by Foucher et al success rate was $93.8 \%$ and failure rate was $6.2 \%$. Another study by Schaff et al success rate was $97 \%$ and failure rate was $2.5 \%$.,10 $^{9,10}$

In contrast studies in unsupervised group conducted by Thaker RV et al success rate was $5.4 \%$ and failure rate was $91 \%$ Ojha $\mathrm{N}$ et al reported success rate of $15 \%$ and failure rate of $45 \%$. Success rate was $17.4 \%$ and failure rate was $82.5 \%$ in the study by Mishra $\mathrm{N}$ et al..$^{5-7}$ The foreign studies were conducted on supervised group of patients. Their success rate are slightly more than our supervised group success rate because India is a developing country, most of the patients are less aware and non-compliant to medical abortion. Although the success rate on unsupervised patients in our study is comparable to other studies conducted in India on unsupervised patients.

\section{Intervention requirement}

In our study in the supervised group $71.4 \%$ patients did not require any intervention which was only $13.8 \%$ in unsupervised group. $86.2 \%$ in the unsupervised group 
resulted in intervention in the form of medical management, surgical evacuation and laparotomy for ruptured ectopic pregnancy. From this data we interpret that unsupervised medical abortion can lead to life threatening complications. Studies in supervised group had similar findings. Study by Schaff et al, $97 \%$ did not require intervention and $2.3 \%$ required surgical evacuation. ${ }^{10}$ Another study by Faucher $\mathrm{P}$ et al, $93.8 \%$ patients did not require intervention and $6.2 \%$ required surgical evacuation. ${ }^{9}$ Studies on unsupervised group showed similar results, study conducted by Mishra $\mathrm{N}$ et al $46.5 \%$ require surgical evacuation, medical management in $33.7 \%$ and $2.3 \%$ patients underwent laparotomy. ${ }^{9,10}$ Another study conducted by Thaker RV et al $75.6 \%$ patients requires surgical evacuation, $5.4 \%$ patients required laparotomy and $5.4 \%$ patients did not require any intervention. ${ }^{6}$ Ojha $\mathrm{N}$ et al. reported $56 \%$ requiring surgical evacuation and $13.3 \%$ required laparotomy.

Based on our study, we recommend, that medical abortion in the first trimester should always be taken under the supervision of a registered medical practitioner linked to the government hospital. The unsupervised use of drug as over the counter drug should be stopped as this can endanger life.

\section{CONCLUSION}

In the present study we conclude that first trimester medical abortion under supervision is more effective, safe and convenient as compared to unsupervised medical abortion. From this study we concluded, that there is no statistical difference between the two groups based on age group, education, socio-economic status and period of gestation. Success rate was observed more in the supervised group as compared to the unsupervised. Most of the patients in unsupervised group undergo failure and required surgical evacuation and even few patients required laparotomy for ruptured ectopic. Regarding safety we observed that complications like pain, heavy bleeding, and shock were more associated in the unsupervised group and some had severe anaemia, required blood transfusion.

\section{ACKNOWLEDGEMENTS}

The author would like to thanks Guide Dr. Rita Ranjan, M.D., Sr. Specialist (HOU) obstetrics and gynaecology department, for her guidance and enthusiastic efforts for completion of this thesis. And deeply indebted to Coguide, Dr. Megha Batra, M.S, Medical officer, DDUH, New Delhi, for her untiring help, constant encouragement and suggestions without which this study would not have completed the wish to thank her parents Dr. S.C Verma and Mrs Renu Verma for their blessings and strength in every phase of my life. Author especially like to thank her husband Dr. Sujit Kumar for his constant support.

Funding: No funding sources

Conflict of interest: None declared

Ethical approval: The study was approved by the Institutional Ethics Committee

\section{REFERENCES}

1. Kulier R, Gülmezoglu AM, Hofmeyr GJ, Cheng LN, Campana A. Medical methods of first trimester abortion. Cochrane Database of Systematic review. 2011;(2):CD002855.

2. International consensus conference on non-surgical medical abortion in early first trimester on issues related to regimens and service delivery. Frequently asked questions about medical abortion, Geneva; 2006.

3. Ellertson C, Waldman SN. The Mifepristonemisoprostol regimen for early abortion. World Health Rep. 2011;1;184-90.

4. Clinical practice guideline: miscarriage management from Royal Women's Hospital; 2010.

5. Ojha N, Bista KD. Situation analysis of patients attending TU teaching hospital after medical abortion with problems and complications JNMAN Nepal. Med Association. 2013;53(19):466-70.

6. Thakar RV, Deliwala KJ, Shah PT. Self-medication of abortion pill. Women Health in Jeopardy. NHL Journal of Medical Sciences. 2014;3(1):26-31.

7. Mishra N. Unpreceded use of medical abortion can be injurious to health. Journal of Evaluation of Medical and Dental Sciences. 2013;2:856.

8. Deshpande S, Yelikar K, Deshmukh A, Kanade K. Comparative study of medical abortion by mifepristone with vaginal misoprostol in women $<49$ days versus 50-63 days of amenorrhea. $\mathrm{J}$ of Obstetrics and Gynaecology of India. 2010;60(5):403-7.

9. Faucher P, Baunot N, Madelenet P. The efficacy and acceptability of mifepristone medical abortion with home administration of misoprostol provided by private providers linked with the hospitals. Gynecol Obstet Fertility. 2005;33(4):220-7.

10. Schaff EA, Stadalius LS, Eisingr SH, Franks P. Vaginal misoprostol self-administered at home after mifepristine for abortion. $\mathrm{J}$ fam ptarc. 1997;44(4):353-60.

Cite this article as: Verma $S$, Ranjan $\mathrm{R}$, Batra M. Case control study of supervised and unsupervised medical abortion in first trimester of pregnancy. Int J Reprod Contracept Obstet Gynecol 2016;5:2367-71. 